\title{
Comparative Approaches between Regular Education and Special Education in the Context of Inclusive School Practices
}

\author{
Nicoleta Ramona Ciobanu* \\ Assistant Professor, PhD, University of Oradea, Faculty of Humanistic and Social Sciences, Universitătii Street, \\ no.1, 410087, Oradea, Bihor County, Romania
}

\begin{abstract}
*Corresponding Author: Nicoleta Ramona Ciobanu, Assistant Professor, PhD, University of Oradea, Faculty of Humanistic and Social Sciences, Universitătii Street, no.1, 410087, Oradea, Bihor County, Romania
\end{abstract}

\begin{abstract}
Along with the "ordinary" children in the primary school, children with different deficiencies are also forced to accept with difficulty the exigencies of the environment in which they live, an environment that can assimilate, tolerate or reject them. These difficulties are of a general, professional, psychological and social nature. School education in integrated education has demonstrated that solving the problems children encounter in the educational process lead to a multi-level analysis of learning issues, depending on the orientation and the perspective of approaching them problems. The difficulties of integration are not generated by the nature of the deficiencies or special needs of pupils in primary education, but also by the way in which practitioners and theorists of education "see things". Integration does not mean including children with deficiencies in ordinary programs without the necessary training and support, ignoring strict needs the individual child and the isolation of children with deficiencies included in the program for inclusion in ordinary schools.

Essentially, inclusion means educating children with special needs / special educational needs and / or deficiencies in ordinary schools, providing specialized services in the ordinary school, and supporting teachers appropriately, and in terms of normalizing school life for the child with special needs, educational practice has shown that for any decision to integrate are important: the individual, the group, the curriculum.
\end{abstract}

Keywords: Inclusive School; Special Education; Education; Quality Of Teaching; Equity In Education

\section{TheOretical Fundamentals}

\subsection{Defining Concepts}

Special education aims especially at adapting the instructional-educational process and rehabilitating the recovery of people who fail to reach the age-appropriate education and social levels within the general (regular) education system. The concept of special education is currently used alternately with the education of special educational requirements.

Special Educational Requirements (ESCs) designate those specific needs or needs related to or not derived from a deficiency that are complementary to and complementary to the general objectives of child education.

Integrated education is also a form of special education that takes place under conditions other than those existing in special schools and seeks to remove the perception of special schools as segregation school units. Educating children with ESCs and / or with deficiencies in ordinary schools, providing specialized services in the ordinary school, and supporting teachers appropriately involves integrated education.

\subsection{Comparative Approach between Integrated Education and Special Education}

Assistance to children with special needs for school, professional and social integration, promotion and guaranteeing the right to education for all children, increasing the quality of teaching and learning practices, ensuring equity in education, equal chances, early intervention and increasing the quality of educational services offered children with special educational needs or children in difficulty are current school policy priorities. 
The implementation of TEMPUS, UNICEF, PHARE, MEC training in integrated education and child protection has led to substantial community-wide changes in demand and supply of child-focused services. Running the process of school integration as early as 1994/1995, initially as isolated experiences / projects, later articulated in a county school integration program, as well as the national program of generalization of actions for the modernization of the special education instituted by order of the Ministry of National Education in 2000, allowed the exploitation of the theoretical and, above all, practical experiences at local level. The evolution of the Romanian school policy towards integrated education implies new guidelines at institutional level: school units, organization of support services, educational management. In this context, the special school represents a major resource in supporting the school integration of children with deficiencies, being, through its specificity, a school integration structure. This is explained by the fact that special schools have the task of integrating children with severe deficiencies: mental deficiencies associated with (language, psycho-emotional, behavioral, etc.). For pupils with such deficiencies, even special education presents as a form of inclusion (as compared to residential medical institutions).

The real chance for the existence of integrated education is only with the special education. From the point of view of the ordinary school, the functionality of the special school also involves the existence and articulation of information and counseling of teachers in general schools, parents and the community on issues related to teaching to children with ESCs.

There may be risks associated with how this external support / support are made between the special school and the ordinary school. If the special school focuses only on ensuring the transfer of responsibility for children with mental and / or associated deficiencies (passing from Specialty to the ordinary school), rather by addressing individual problems, there may be a risk of failure to integrate and return in the special school. However, if the special school function focuses mainly on prevention rather than on "treatment", on a curricular approach and on formative support, then it is more likely that the ordinary school will develop the skills needed to solve the situations of educational risk.

Working as a resource center, special school can be a source of information and advice in the field of special education. Formal relationships between the special and the ordinary school can facilitate the interaction between the students and the teachers in the two schools; can provide the necessary assistance for the ordinary school that integrates the children with deficiencies and the development of the curriculum and resources of both schools.

Cooperation ties are often the result of the initiative and the efforts of directors or members of the teaching staff of those schools. Beyond the idea of a "threat" to special schools in the context of enhancing integration attitudes and practices, teachers initiate cooperative relations with ordinary schools in order to facilitate, through a series of gradual steps, the transition from the special school to the usual one. Another context of cooperation is related to the capitalization of the specialized experience and the resources of the special school for the other ordinary schools in the education of children with integrated and / or educational needs.

\section{RESEARCH METHODOLOGY}

\subsection{Purpose of Research}

The aim of the research is to determine the integration opportunities for pupils with special educational needs (ESC) starting with the primary school cycle, starting from the peculiarities of pupils in the primary school of special schools.

\subsection{Objectives of Research}

The research objectives are as follows:

- studying the attitudes of the teachers in the integration school and the special school towards the pupils with ESC and the integration process;

- an analysis of social representations towards deficiency and / or disability and integration of teachers in mass school and special schools; 
- Developing a model for changing / forming positive attitudes of teachers towards children with ESCs and their integration, a program that can be applied in the current practice.

\subsection{Hypothesis and Variables of Research}

General hypothesis: The effectiveness of integrated education depends on the quality of school management and the age of the child at the start of school activities.

\subsubsection{Specific Assumptions}

Hypothesis 1 - There are significant differences between pupils with special educational needs in the integration school and those in the special school in the sense of structuring cognitive processes and personality structuring.

Hypothesis 2 - There are significant differences in the management of the integration school and the special school.

Hypothesis 3 - There are more advantages than disadvantages in inclusive primary education.

\subsubsection{Research variables}

The independent research variable is "cooperation between the school ordinary school and special school ".

The dependent variable of the research is: "advantages / disadvantages of the school integration of students with special educational needs in the primary cycle".

\subsection{Sample of Research}

The research was carried out on two lots of 20 teachers/special education teachers from integrated education and special education respectively. The subjects in integrated education are holders of schools in the town of Șimleul Silvaniei, Sălaj County, Romania and have a departmental age of 4 to 30 years. Teachers covered by this research are enrolled in the School of Inclusive Education School from Şimleul Silvaniei, having seniority in education between 4 and 30 years.

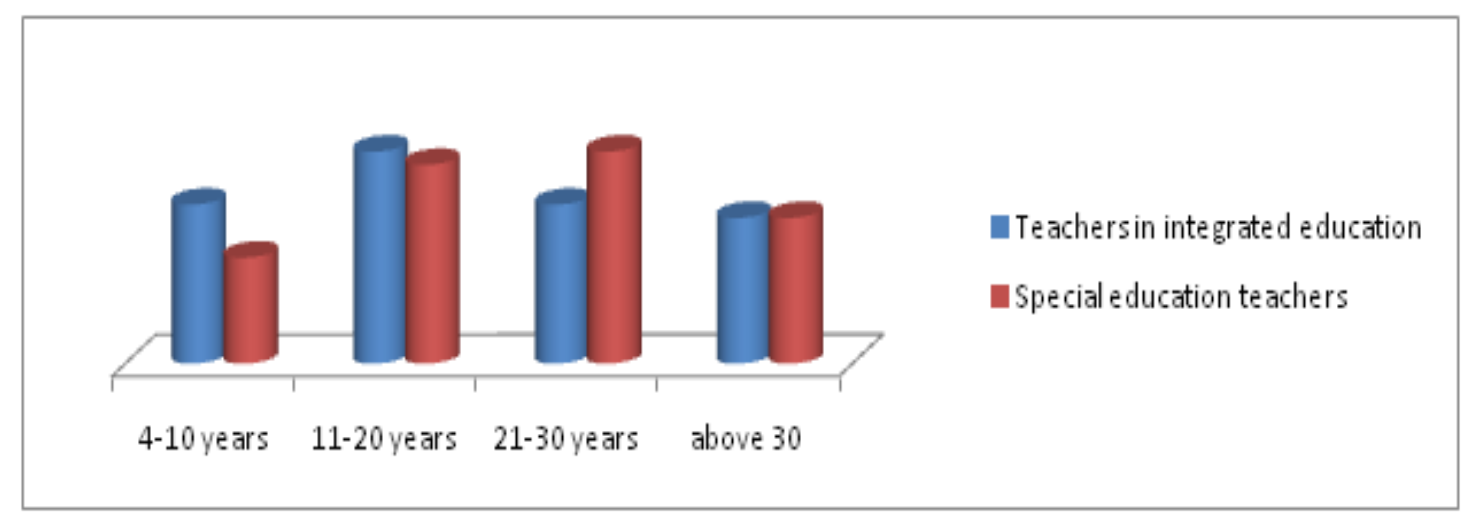

Fig1. Distribution of subjects by seniority in education

\subsection{Research Methods}

The research aims to analyze the differences between pupils with ESLs in integrated education and pupils in special education, the advantages and disadvantages of integrating into the regular education of pupils with ESCs. Particular importance is given to teachers' suggestions to optimize the potential disadvantages of integration. In order to be able to analyze these issues, we used a questionnaire with 10 open-access questions (Appendix 1). The questionnaires were applied between $1^{\text {st }}$ and 31 of January 2018, individually for the teachers included in the investigation teams.

\subsection{The Results of the Research}

Hypothesis 1 - There are significant differences between pupils with special educational needs in the integrative school and those in the special school in the sense of structuring cognitive processes and personality structuring. 


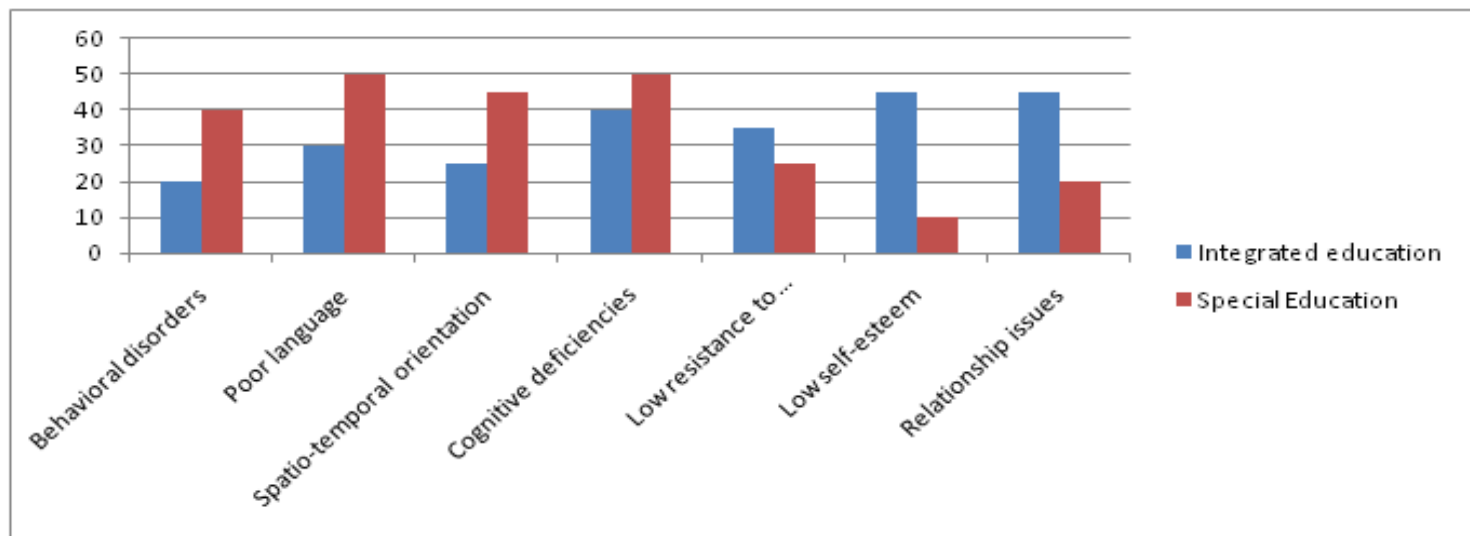

Fig.2. Frequency of psycho-pedagogical features in pupils with ESCs in special education and integrated pupils in integrated education

\subsubsection{Qualitative Interpretation of Results}

From the comparative results, it is clear that students with special educational needs in SEE have a significant proportion of their behavioral disorder, which have more serious difficulties in spatialtemporal orientation, have $100 \%$ language disorder, and, as a whole, obvious cognitive deficiencies, compared to students integrated in ordinary education.

However, integrated students have low resistance to frustration manifested through non adaptive conduct, low self-esteem, obvious and worrying difficulties in integrating into the school micro group (relational issues). The significantly increased frequency of these latter features is explained by the fact that pupils with ESCs in special education have a relatively good self-esteem because they are part of homogeneous groups and have no ability to self-assess their own school failures, school regresses sometimes. In addition, the didactic and therapeutic compensatory strategies favors in the context of special education differentiated treatment and learning at its own pace.

It may seem like a paradox that, despite the more serious, often associated deficiencies, pupils in special education do not have as many problems as in the case of pupils in inclusive education. This is explained by the existence of classes, groups of maximum 8-10 pupils with moderate mental dexterity and maximum 4-6 pupils with severe mental deficiency, through classroom management strategies, by including in the same therapeutic programs: language therapy, physiotherapy, ludotherapy, and occupational therapy of all students in the class.

Hypothesis 2 - There are significant differences in the management of the Integrative School and the Special School.

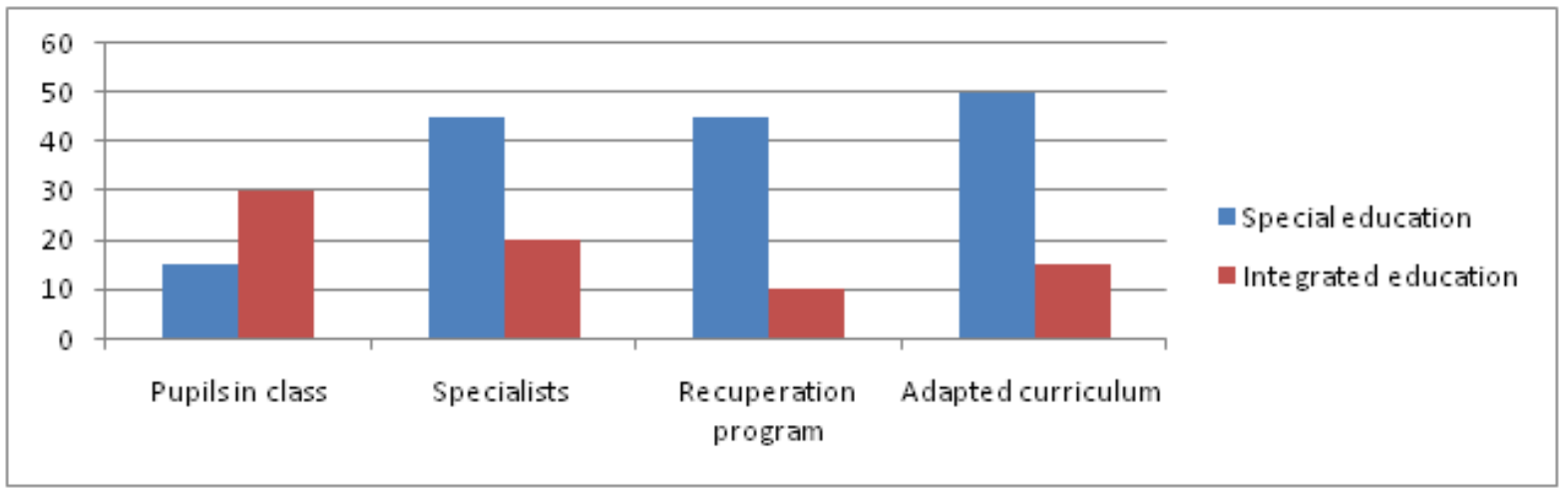

Fig3. Frequency of key issues regarding the management of special schools and schools integrative

The integrative school, specially designed for schooling, integrates 1-2 students with CES into 12-15 pupils' class. Both the special education teacher and the integrated education teacher develop a curriculum tailored to the needs of students with ESCs and their assessment is differentiated in relation to that curriculum.

Other parameters of the school management are the interdisciplinary team component and the 
recuperation program. In special education, the interdisciplinary team consists of a special teacher of psycho-pedagogy, teacher / teacher educator, physiotherapy, speech therapist, psychologist, social assistant, physician, each having specific tasks in initiating, applying and monitoring the implementation of personalized intervention programs. Students benefit from an instructiveeducational and rehabilitative-therapeutic program for 8-10 hours / daily.

In integrated education, the spy professor works with a number of 13 students and provides: cognitive, psychomotor and ludotherapy therapy. Along with him, the interdisciplinary team includes: the speech therapist (in the schools where there are), sometimes the school psychologist who serves both the high school and the pupils with special educational needs, and which is sometimes assigned to two schools and of course teacher. The multiplication and diversity of the problems to be solved by this interdisciplinary approach in integrated education is obviously to the advantage of the integrated students.

Hypothesis 3 - There are more advantages than disadvantages in inclusive primary education

Advantages of integration seen by:

\begin{tabular}{|ll|ll|}
\hline Teachers in special education & Teachers in integrated education \\
\hline a) & for students: & a) & for students: \\
- & students go to schools near home & - & enhancing students with ECSs \\
- & avoiding stigma & - & effective recovery \\
- & great program & - & assimilation of knowledge in its own rhythm \\
- & equal chances & - & developing the spirit of cooperation \\
- & access to regular education & - & developing skills \\
& & - & specialized support \\
b) & for teachers & - & positive models \\
- & there are no teachers with over 25 years \\
of experience & b) & for Teachers: \\
- & partnership in class & - & the new experience \\
- & widening skills & - & the desire for self-denial \\
- & knowledge of social reality & - & broadening the professional horizon \\
\hline
\end{tabular}

Disadvantages of integration seen by:

\begin{tabular}{|c|c|}
\hline Teachers in special education & Teachers in integrated education \\
\hline $\begin{array}{ll}\text { a) } & \text { for pupils and their families } \\
- & \text { risk of discrimination } \\
- & \text { school failure } \\
- & \text { frustration } \\
- & \text { I do not keep pace with my colleagues }\end{array}$ & $\begin{array}{l}\text { a) for pupils and their families } \\
-\quad \text { reducing the time available to ordinary } \\
\text { students }\end{array}$ \\
\hline $\begin{array}{ll}\text { b) } & \text { for teachers } \\
- & \text { risk of overloading } \\
- & \text { stress } \\
- & \text { extra effort } \\
- & \text { neglect of children without ESCs } \\
\end{array}$ & $\begin{array}{l}\text { b) } \text { for teachers } \\
-\quad \text { a lot of work } \\
-\quad \text { low motivation } \\
-\quad \text { lack of professional training of teachers to } \\
\text { work with students with ESCs }\end{array}$ \\
\hline
\end{tabular}

In the teachers' opinion inclusive education in primary school has more advantages for the pupil than disadvantages. Teachers in special education support less the integration process. An explanation would be the fear of abolishing special education, which would put their job at risk. Another explanation is that special schools benefit from specialists' cabinets, and the classes have a small number of pupils. Teachers in integrated education enumerate several advantages of integrating students with ESCs into a classroom and fewer disadvantages. In this regard, we have found that most of them have experience in conducting the teaching process in an inclusive school.

The special school is a major resource in supporting school integration of children with deficiencies, being, by its very nature, a school integration structure. This is explained by the fact that special schools have the task of integrating children with serious deficiencies: mental defects associated with (language, psycho-emotional, behavioral, etc.). For students with such deficiencies, even special education presents as a form of inclusion (compared to residential-medical institutions). The special school may be a source of information and advice in the field of special education. Formal 
relationships between the special and the ordinary school can facilitate the interaction between the students and the teachers in the two schools, can provide the necessary assistance for the ordinary school that integrates children with deficiencies and the development of the curriculum and resources of both schools.

Beyond the idea of a "threat" to special schools in the context of enhancing integration attitudes and practices, teachers initiate cooperative relations with ordinary schools in order to facilitate, through a series of gradual steps, the transition from the special school to the usual one. Another context of cooperation that I have found and applied in my teaching practice is related to the capitalization of the specialized experience and the resources of the special school for the other ordinary schools in the education of children with deficiencies.

\section{CONCLUSIONS AND RECOMMENDATIONS}

From the data presented it is found that the inclusive education of pupils with special educational needs is efficient starting with the primary school cycle in the conditions of an adequate management.

Teachers, who were the subjects of research, see the process of integration as a normal thing that should begin even from the preschool stage and continue at least until high school. In order to optimize the disadvantages, it is suggested to reduce the number of students in the classroom and to a support teacher (maximum 6 students), to improve the teachers in the university centers and to pay more attention to inclusive schools from the community. Teachers consider that support teachers should allocate a number of hours to counsel parents of pupils with special educational needs and to work with the teacher. It also suggests greater involvement of school inspectorates in promoting the processes of integration of pupils with special educational needs by materially endowing the support teachers' cabinets and by training teachers to teach an inclusive class.

We found that teachers with less than 10 years of age have greater openness to inclusive education than teachers with over 25 years of seniority at the department. For the success of school integration of pupils with ESCs, it is advisable that the interdisciplinary team be made up of professionals. We can see the diminishing of the differences between the special school and the ordinary school on the school management line. The ordinary school tends to become more and more a public institution that can meet the various requirements of schooling from the schooling of the gifted pupils to the integration of those with deficiencies.

Application of integrated education does not exclude special education. In fact, integrated education is also a form of special education that takes place under conditions other than those existing in special schools. However, integration into this context must be supported by specific educational measures at the macro-school level and at the level of each integration school.

\section{REFERENCES}

[1] Ainscow, M. (2005). Developing inclusive education systems: what are the levers for change?. Journal of educational change, 6(2), 109-124.

[2] Banciu, V., \& Peter, K. M. (2014). Children with learning difficulties a challenge for teachers, In INTED2014 Proceedings (pp. 2402-2410). IATED.

[3] Booth, T., Nes, K., \& Strømstad, M. (Eds.). (2003). Developing inclusive teacher education. Routledge.

[4] Salvia, J., Ysseldyke, J., \& Witmer, S. (2012). Assessment: In special and inclusive education. Cengage Learning.

\section{APPENDIX}

Questionnaire

The purpose of this questionnaire is to analyze the opportunities of integration of children with ESCs (special educational needs).

1. What do you think about the process of integrating CES children?

2. What do you think are the differences between the pupil with CES integrated in an ordinary class and his colleagues in terms of the psycho-pedagogical profile?

3. List at least two peculiarities of the adaptation process of a CES student compared to his classmates 
in the integrated class.

4. Summarize in a few words key issues regarding:

a) organizing inclusive classroom / homogeneous class collectives.

b) the didactic and recuperation process (curriculum, classroom, evaluation)

c) the school-family relationship.

5. What do you think are the benefits of school integration?

a) for pupils and families

b) for teachers

6. What do you think are the disadvantages of school integration?

a) for pupils and families

b) for teachers

7. Give three suggestions for optimizing the potential disadvantages of integration:

8. When do you consider it appropriate for a child with ESC to be included in the integration process?

9. How do you see the role of the support teacher in the interdisciplinary team?

10. What do you think should be the involvement of County School Inspectorate in the process of integration?

Didactic function:

Age of education:

Mark of class you are teaching:

a) ordinary b) inclusive c) special

Citation: Nicoleta Ramona Ciobanu. "Comparative Approaches between Regular Education and Special Education in the Context of Inclusive School Practices". International Journal of Humanities Social Sciences and Education (IJHSSE), vol5, no.5 2018, pp. 12-18 doi: http://dx.doi.org/10.20431/2349-0381.0505002.

Copyright: (C) 2018 Authors. This is an open-access article distributed under the terms of the Creative Commons Attribution License, which permits unrestricted use, distribution, and reproduction in any medium, provided the original author and source are credited. 